\title{
Study on Teaching of Minority Nationality Sports in College Sports
}

\author{
Bo Xiao $^{1}$ \\ ${ }^{1}$ Sichuan Minzu College, Kangding, Sichuan, 626001
}

KEYWORDS: Minority Nationality Sports; College Sports; College Teaching

\begin{abstract}
In the new century, we have ushered in a golden opportunity, "Western Development" and a new round of curriculum reform, which has brought a golden opportunity for the development of university sports education ethnic areas, we should seize the opportunity to present Scientific under the guidance of Marxist ideology education, strengthen school sports, earnestly implement the "State Council on basic Education reform and development" and "New Standard" proposed "health first" and "to promote their moral, intellectual, physical comprehensive development "requirements. So, how our nation area colleges according to the actual situation of the development and use of Minority Traditional Sports in the region; how to use these programs for students with physical education, promote their full development; how to improve the quality of teaching in universities is minority areas posing a major issue before us.
\end{abstract}

\section{Introduction}

National Committee on Traditional Sports Culture of Minority Nationalities Affairs held the first seminar for the first time the concept of Traditional Ethnic Sports in the discussion, and the formation of a variety of effective, theoretical concepts of high academic value, but has not yet formed a species recognized concept. Some scholars believe that the study of history from the perspective of "national traditional sports means of pre-modern competitive sports and recreational activities. Because later introduced into China of Western modern sports, traditional sports in social life, especially in the cities and the army's influence in schools sharply weakened, in addition to martial arts was also a strong advocate, the other has a small range of activities, these studies often referred to as the national traditional Sports traditional Sports. minority traditional sports concept more precise, and the traditional concept of minority sports defined as long-term spread in our country, and the remaining 55 ethnic minority groups in addition to the Han nationality, have the characteristics of the national culture and a variety of physical activities have a strong physique and physical and psychological effects of entertainment in general.

\section{Features and Functions of the National Traditional Sports}

Competitive in terms of cultural development point of view, with the introduction of human self-awareness and sense of community, self and others took my group to distinguish the group with him, and competition is inevitable. Since the sense of competition, humanity sports activities also began competitive features.

Ours is a diverse nation with 56 countries, each nation has its own unique multi-geographical environment, natural conditions, lifestyle and compatible with the physiological and psychological recreational activities that meet the different nationalities, different levels of people have the required characteristics of a variety. 
Strong national colors of different nationalities have their own national sports rich colors, they work closely with the nation's own social life together, ethnic customs, lifestyles and more production by the respective national sport expression.

Financial fitness and entertainment in one of a variety of traditional national sport, often associated with music, dance, music and dance, both physical and mental recreation and achieve the purpose of fitness. Such as the Hmong dance Lusheng, music, dance and gymnastics, martial arts blend together, when performers play Lusheng, various actions performances simultaneously. Traditional sports such stylistic combination of both light and intense, not only exercise the body and gives the joy of beauty.

Minority interest in traditional sports of many projects due to the historical development, the relatively weak competitive on the influence of the traditional characteristics of the nation, as well as changes in the origin and development of heritage, more emphasis on the nation's public health, entertainment, so that more people involved into various forms, easy to learn content, and combine fitness with entertainment which, by all sectors of the nation loved and respected, to be baptized after thousands of years, still has a broad mass base.

Minority Sports economy mainly concentrated in ethnic enclaves, because our country is still in the ranks of developing countries, the majority of ethnic enclaves are relatively backward economy, sports and sports equipment lag lack of infrastructure, through the Millennium heritage, development of ethnic minorities in the project, gradually lower space requirements, in streets, fields, indoor and outdoor can be carried out, according to their needs and level of development of consumption, investment, or do not exercise very little investment can be carried out, both economical and effective.

\section{Feasibility Analysis of College Minority Traditional Sports}

Category Traditional Ethnic Sports Items numerous, its surface characteristics determine the popularity of conduct is extremely broad, and the multiplicity of its functions make up the limitations of competitive sports, traditional ethnic sports have been the College Physical Education of basic conditions. The school is an important part of modern sports development, but also towards the standardization of traditional sports, is one important way scientific. Most of the Olympic Games in modern times have been school-based development to a high level of competitive development process.

Minority Traditional Sports and lifelong education is lifelong sports school sports, family sports, community sports convergence together, maintaining the integrity and continuity of physical education, fitness for life in harmony goal. Target Characteristics of Minority Traditional Sports and Lifelong Physical goal is unity. Because of minority sports project extensive content, lower equipment and other requirements of the site, activities simple way, by popularizing after school, suitable for lifelong physical fitness.

Minority Sports and Education for science and orderly school physical education activities not only enable students to enhance physical fitness, but also the quality of the culture will promote the development of students' mental health, so that students get the harmonious development of body and mind. School sports disciplines have other irreplaceable role in the implementation of quality education. Minority sports emphasis on health and physical pleasure and common development properties, as well as various forms, easy to learn, in the course of quality education is more conducive to students being accepted and carried out. Spirit of minority sports culture rich culture and national spirit, harmony and quality education, make the national traditional culture heritage and enhance national cohesion. 
Minority Sports and advantages of conditions for carrying out the College along, Physical Education Content in University of Sports around the project to carry out, there is no specific teaching content, greater exercise intensity, in the form of a single movement, learning difficulties, teaching means of a single, more than serious, lively enough, not enough teaching content to adapt to the requirements of fitness. Through the four universities in over 10 national sample survey of 558 students that the students are very fond of traditional ethnic sports, accounting for 93.7 percent of boys, girls accounted for $96.3 \%$, and showed great interest in learning, while they also hope to carry out the traditional school sports such minorities. Minority Traditional Sports can not only improve students' physical fitness through exercise, can also guide students to the nation's outstanding traditional culture and heritage, carry forward the national spirit, foster national pride, improve the overall quality of students.

\section{The Teaching method of Minority Sports in Colleges}

The school is a very important part of the development of Minority Traditional Sports, is an important way the original ecological national sport toward standardization and scientific popularization. School sport is a fundamental power of the people strong, Physical Education plays an important role in the whole education system. 5 National College of Physical Education Teaching Guidelines promulgated by the former State Education Commission had clearly stated in 6: lessons outstanding sports achievements in the world and promote the combination of traditional national sport, physical education textbooks should pay attention to the times, diversity, and to fully reflect the textbook National and Chinese characteristics. Colleges and Universities in Minority Sports can greatly enrich the content of college sports curriculum, and the previous single competitive sports to diversify teaching content and methods of teaching minority sport shift.

To carry out the contents of Minority many minority sports, the project may be carried out in schools of minority sports is also very much, since in recent years, has entered the martial arts sports teaching various colleges and universities, and by college students love to make this martial arts a traditional national sport is an important branch to carry forward the tradition, and a step by step to the world, has also been recognized by national people's favorite. Traditional ethnic sports in our colleges and universities to carry out content to have long-term strategic objectives, select easy to spread, health content, with ethnic characteristics of traditional sports project, to give priority to the development and take advantage of advantageous resources and scientific strength of the school, were excavation and finishing, Quweicunzhen, on which many of the best content portion refining, improvement and innovation, to make it more in line with modern sports development ideas, to standardized and scientific direction, more in line with the spirit of the times.

Organization of National Traditional Sports is not perfect, national sport talent shortage. The PE Teachers mostly have good professional ethics and professional skills, understand the law of education and sports teaching of law, active, capable of binding characteristics of teaching quality education, effectively compensate for the lack of national sports worker shortage. Venues and facilities is relatively good universities, research and conducive to minority sports, through teaching university national sport, scientific discovery is more suitable for the whole society to the promotion and development of minority sports, to explore for Minority Sports Development road, lay the foundation for minority sports in schools at all levels to carry out. Physical characteristics of minority rich sports content teaching colleges and universities, so that students in a relaxed environment, access to physical and mental health in the cheerful pleasant state of mind. Teaching Minority Traditional Sports to improve students' psychological needs of the national culture, establish a good sports concept, lifelong exercise habits, the development of traditional national 
sports, promote national culture, to enable students to become high-quality synthetic quality talents have far-reaching practical significance and promotional value.

\section{Conclusion}

Traditional ethnic sports combined with the actual school after appropriate improvements, is fully incorporated in College Physical Education. Minority Sports in College Physical Education in favor of the rich content of Physical Education College, so that teaching content diversification, flexibility and individualized help to improve the structure of college sports teaching system, so that diversity and the localization, contributing to the development with local Featured Sports College classroom characteristics and local flavor.

\section{Acknowledgements}

Proj.: Study on the Development and Innovation Strategy of Modern Kang-pa Sports Culture Dissemination." Key Project of Humanities and Social Sciences of Sichuan Provincial Education Department in 2015

Project NO.: 15SA0138

\section{Reference}

[1] Fan Benqi, Yang Hui. Traditional Sports and School Sports Fusion Research and Development [J]. Anhui Sports Science, 2008, 29 (2).

[2] An Dou. Physical Education and Sports Project on Ethnic Groups in China to Enter The School [J]. China Sport Science and Technology, 2003, 39 (3).

[3] Shao Yuping. Comparative Study of The National Traditional Sports Culture and Western Sports Culture [J]. Sport Science \& Technology, 2009, (8).

[4] Qiao Liang. Traditional Sports Research Issues Joe Beam Minority Thinking [J]. Capital Institute Of Physical Education, 2010, 22 (2). 